\title{
Developing Preceptors through Virtual Communities and Networks: Experiences from a Pilot Project
}

\author{
Margaret L Ackman and Marcel Romanick
}

\begin{abstract}
Background: Supporting preceptors is critical to the expansion of experiential learning opportunities for the pharmacy profession. Informal learning opportunities within communities of practitioners are important for hospital preceptors. However, such communities may be limited by geographic separation of preceptors from peers, faculty members, and supports within the pharmacy services department.
\end{abstract}

Objective: To use computer-mediated conferencing to create a sense of community among preceptors, specifically by using this medium to provide initial development of and continuing support for preceptors, and to examine preceptors' satisfaction with this approach.

Methods: Thirty-nine preceptors who had completed a day-long face-toface preceptor development workshop and who were supervising students in 1 of 2 specific rotation blocks were invited to participate in the study. The pharmacists used computer-mediated conferencing to meet for virtual networking about specific topics. They met once before the student rotation to receive instructions about the technology and to discuss student orientation and scheduling, and 3 times during the student rotation for open discussion of specific topics. Evaluation and feedback were solicited by means of an electronic survey and virtual (i.e., computerbased) feedback sessions with an independent facilitator.

Results: The response rate was $66 \%$ (26/39) for the electronic survey, but only $15 \%$ (6/39) for the virtual feedback sessions. All of the respondents were experienced preceptors, but for $92 \%$ (22/24), this was their first experience with computer-mediated conferencing. Overall, the sessions had a positive reception, and participants found it useful to share information and experiences with other preceptors. The main challenges were related to the technology, perceived lack of support for their participation in the sessions, and inconvenience related to the timing of sessions.

Conclusion: Computer-mediated conferencing allowed preceptors to learn from and to support each other despite geographic distance. The participants felt that these sessions encouraged them to serve as preceptors regularly. Such encouragement could contribute to the retention of preceptors, which is important to the expansion of experiential learning.

Key words: preceptorship, computer-mediated conferencing, students

\section{RÉSUMÉ}

Contexte : Le soutien des précepteurs est essentiel à l'expansion des occasions d'apprentissage par l'expérience pour la profession de pharmacien. Les occasions d'apprentissage informel au sein des collectivités de praticiens sont importantes pour les précepteurs hospitaliers. En revanche, de telles collectivités peuvent être limitées, car certains précepteurs sont géographiquement séparés de leurs pairs, des membres du corps professoral et du soutien au sein des services de pharmacie.

Objectif : Recourir aux outils de téléconférence assistée par ordinateur pour créer un sentiment d'appartenance à une collectivité parmi les précepteurs, plus particulièrement en utilisant ces outils comme moyen de perfectionnement initial et de soutien continu des précepteurs, et évaluer la satisfaction des précepteurs relativement à cette approche.

Méthodes : On a invité à participer à cette étude 39 précepteurs qui avaient terminé un atelier d'une journée en face en face sur le perfectionnement des précepteurs et qui supervisaient des étudiants dans une des deux périodes de stage définies. Les pharmaciens ont utilisé la téléconférence assistée par ordinateur pour des rencontres virtuelles sur des sujets précis. Ils se sont rencontrés une fois avant le stage des étudiants pour recevoir des instructions sur la technologie utilisée et discuter de l'orientation des étudiants et de la programmation de leur stage, puis à trois reprises durant le stage des étudiants pour des discussions ouvertes sur des sujets précis. On a sollicité l'évaluation et la rétroaction des précepteurs au moyen d'un sondage électronique et de séances de rétroaction virtuelles avec un animateur indépendant.

Résultats : Le taux de réponse au sondage électronique était de $66 \%$ (26/39) et de seulement $15 \%(6 / 39)$ pour les séances de rétroaction virtuelles. Tous les répondants étaient des précepteurs expérimentés, mais il s'agissait d'une première expérience de la téléconférence assistée par ordinateur pour $92 \%$ (22/44) d'entre eux. Globalement, les séances ont été reçues positivement et les participants ont trouvé utile de pouvoir partager information et expériences avec d'autres précepteurs. Les principales difficultés étaient liées à la technologie, à l'absence apparente de soutien pour leur participation aux séances et aux inconvénients associés au moment choisi pour la tenue des séances.

Conclusion : La téléconférence assistée par ordinateur a permis aux précepteurs de profiter d'un apprentissage réciproque et d'un soutien mutuel malgré la distance. Les participants étaient d'avis que ces séances les encourageaient à s'investir dans le préceptorat sur une base régulière. Cet encouragement pourrait contribuer à la rétention des précepteurs, ce qui est important pour l'expansion de l'apprentissage par expérience.

Mots clés : préceptorat, téléconférence assistée par ordinateur, étudiants

[Traduction par l'éditeur] 


\section{INTRODUCTION}

Caculties and schools of pharmacy throughout Canada are

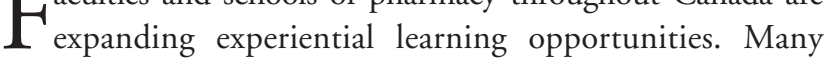
experiential rotations are in institutional practice, so strategies to expand capacity for these learning opportunities are important. Despite various innovative models for experiential learning, the importance of educating and supporting new preceptors and of supporting and retaining existing ones cannot be overstated.

The impetus for this project was the availability of provincial government funding to support experiential learning within various health care professions. Through informal staff feedback, clinical practice leaders in the Edmonton Zone of Alberta Health Services (AHS) had previously identified a perceived lack of support as a factor contributing to lack of interest in serving as a preceptor. Hospital pharmacist preceptors within institutions in this zone of AHS had identified certain challenges unique to their practice setting (hospital compared with community practice, and also academic compared with small community hospitals) but were reluctant to raise these issues with the provincial school of pharmacy. In addition, pharmacists' changing scope of practice in Alberta has created a knowledge and practice gap between how current preceptors were trained (when they were undergraduate students themselves) and the expectations that the Faculty of Pharmacy and Pharmaceutical Sciences, University of Alberta, and the Alberta College of Pharmacists now place on preceptors. AHSEdmonton Zone must also deal with the geographic reality of some preceptors being in locations remote from the faculty, other clinical practice leaders, and other preceptors.

Communities of practitioners can create informal learning opportunities. ${ }^{1}$ We wanted to replicate and support this concept in a virtual environment. The first phase of the project was creation and delivery of a face-to-face preceptor development workshop. The second and third phases, which are the focus of this paper, involved use of computer-mediated conferencing to develop communities or networks of pharmacists to provide further development and support, without geographic restriction. Of particular interest were preceptors' opinions about use of this technology for this purpose.

\section{METHODS}

\section{Setting and Participants}

The Edmonton Zone of AHS serves a population of about 1 million in Edmonton, Alberta, and the surrounding region. It consists of 13 facilities with over 2500 beds, as well as outpatient clinics and public health services. The Pharmacy Services department, which employs nearly 180 pharmacists and more than 150 technicians, provides clinical and distribution services for this zone.

Pharmacy Services also accounts for a substantial propor- tion of institutional rotation sites for students of the University of Alberta's Faculty of Pharmacy and Pharmaceutical Sciences. Preceptors who had completed a full-day, face-to-face preceptor workshop (phase 1; described in more detail below) and who had been assigned a fourth-year student for one of two 6-week rotation blocks were invited to participate in networking sessions via computer-mediated conferencing. Attendance was not mandatory and was not recorded. Preceptors were informed that they would be asked to evaluate both the sessions and the use of computer-mediated conferencing and that this feedback would be used for program development. Clinical practice leaders and the Faculty of Pharmacy and Pharmaceutical Sciences usually provide support to preceptors, so this pilot project was considered an expansion of an existing program, and ethics approval was not sought. Preceptors were grouped on the basis of similarities in practice or areas of interest, regardless of geographic location. The preceptors included people with various levels of experience, specialties, and practice environments.

\section{Technology}

Elluminate Live (Blackboard Inc, Washington, DC) is a live, web-based conferencing system that allows computerized communication and interaction in real time. This platform was selected for the project because it was available through the Faculty of Pharmacy and Pharmaceutical Sciences at no charge and had been used previously by some of the clinical practice leaders. This technology includes the following equipment and functions: microphone, audio, chat, online polling, webcam, and a whiteboard tool, of which we used all but the microphone and webcam. During a session, the facilitator can share applications from his or computer and can transfer files to participants. Each session is presented synchronously, which enables real-time interaction. Sessions can also be recorded for later review, but in the context of this project, session recordings were used solely for the purposes of preceptor development.

\section{Description of Project}

Phase 1 of the project consisted of creation and delivery of an 8-h (1-day) preceptor development workshop to complement resources already provided by the Faculty of Pharmacy and Pharmaceutical Sciences and to address issues unique to hospital practice and/or related to the changing scope of practice (Table 1, Figure 1). For about half of the workshop, participants worked in small groups to identify successful strategies used by experienced preceptors. The workshop introduced the concept of using activity lists, scheduling systems, and literature and resource templates, such as standardized reading lists and clinical tools, to increase the efficiency of preparation for and organization of student rotations. The intent of this phase was to develop a sense of community among the preceptors, based on sharing between experienced and novice preceptors. 
Table 1. Outline of Preceptor Development Workshop

\begin{tabular}{ll} 
Topic & Content \\
\hline Introduction & Definition of preceptorship \\
& Benefits of preceptorship \\
& Barriers to serving as a preceptor \\
& Review of current status of preceptorships within the health region \\
\hline Expectations of preceptors and students & Discussion of framework of expectations for various levels of students \\
& Discussion of expectations related to knowledge, skills, attitudes, \\
& and decision-making \\
& Case-based group discussion of expectations of preceptors \\
\hline How to deliver feedback & Importance of feedback \\
& Issues related to perceptions (of students and preceptors) \\
& and feedback \\
Case-based group discussion of delivery of effective feedback \\
\hline How to teach the process of care & Sharing, discussion, and adaptation of a standard framework to \\
& Discussion of processes by which pharmacists select patients to \\
receive pharmaceutical care & Sharing of individual pharmacists' approaches to preceptor activities \\
and patient care when they have a student \\
Importance of planning \\
Content of orientation \\
Different teaching styles in relation to student progression \\
Use of calendars \\
Concept of shared reading lists \\
Scheduling of feedback \\
\hline How to design a rotation
\end{tabular}

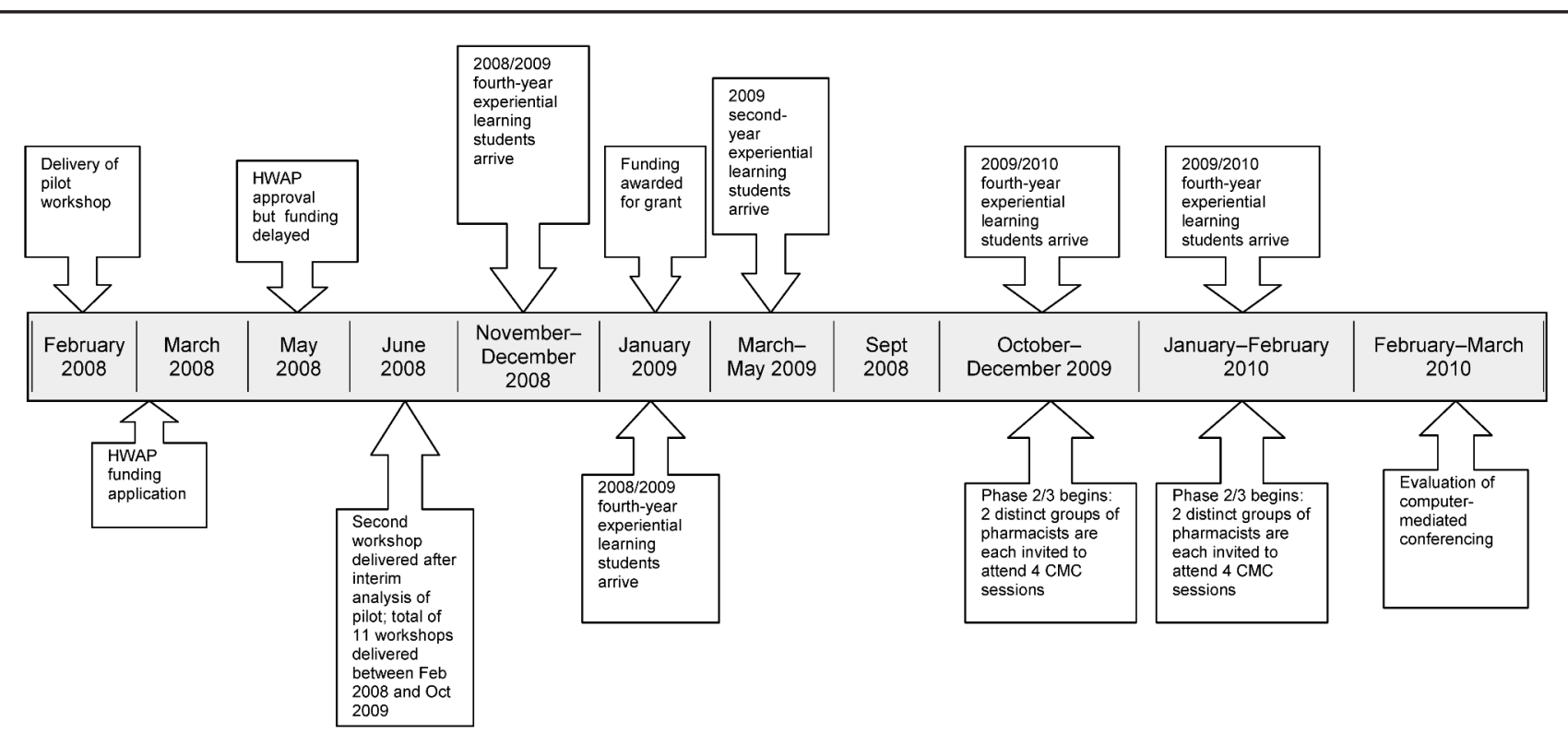

Figure 1. Timeline of a project offering development and support of preceptors by means of computer-mediated conferencing. $\mathrm{CMC}=$ computer-mediated conferencing, HWAP = Health Workforce Action Plan.

Phase 2 was designed to form networks of preceptors before the student rotations, to allow the creation, sharing, and updating of literature and resource templates. Phase 3 was to involve communication within a virtual community of preceptors during an academic student rotation. Restrictions on the timing of academic rotations led to phases 2 and 3 being combined, and only the 39 preceptors who had been assigned students during 2 specific 6-week academic rotations were invited to participate (Figure 1). These preceptors participated in a facilitated computer-mediated conferencing session the week before the rotation began, to receive instructions about the technology and to discuss student orientation and schedul- 


\section{Table 2. Outline for Computer-Mediated Conferencing Sessions*}

\begin{tabular}{|c|c|}
\hline Topic & Objectives \\
\hline \multirow[t]{6}{*}{ Planning and starting a rotationt } & Become familiar with conferencing technology \\
\hline & Group current preceptors with different levels of experience \\
\hline & Draw on experience of community of preceptors \\
\hline & Collate and share good-quality, practical orientation material \\
\hline & Share examples of calendar templates \\
\hline & Discuss preparations for next session (e.g., reading lists) \\
\hline \multirow[t]{5}{*}{ Reading lists, therapeutic topics, and skills $\neq$} & Continue to become familiar with conferencing technology \\
\hline & Discuss progress of current rotations \\
\hline & Discuss workload management, therapeutic topics \\
\hline & Share examples of reading lists \\
\hline & Discuss preparations for next session \\
\hline \multirow[t]{3}{*}{$\begin{array}{l}\text { Feedback, evaluation, and decision-making } \\
\text { (facilitated by experiential learning faculty } \\
\text { coordinator) } \neq\end{array}$} & $\begin{array}{l}\text { Introduce advocacy inquiry, a method of delivering feedback } \\
\text { currently advocated by FoPPS, which explores students' clinical } \\
\text { reasoning ability and supports development of clinical reasoning skills }\end{array}$ \\
\hline & Use advocacy inquiry for a simulated student scenario \\
\hline & $\begin{array}{l}\text { Identify advantages of advocacy inquiry and situations in which } \\
\text { it should be used }\end{array}$ \\
\hline \multirow[t]{4}{*}{ Student evaluations and expectations $\ddagger$} & Discuss current students \\
\hline & Review and discuss FoPPS evaluation forms \\
\hline & $\begin{array}{l}\text { Review and discuss AHS-Edmonton Zone documents regarding } \\
\text { expectations for knowledge, skills, attitudes, and decision-making } \\
\text { for students at various levels in their training }\end{array}$ \\
\hline & Review plans for formal evaluation of pilot project \\
\hline
\end{tabular}

ing. Three additional facilitated sessions, for open discussion of specific topics, took place during the academic rotation. The clinical practice leaders determined the topic and discussion points for each session (Table 2) on the basis of summative evaluation of the phase 1 workshop.

\section{Evaluation}

At the conclusion of each 6-week rotation, feedback was solicited through an electronic survey. The survey was reviewed in advance by a small group of pharmacists to ensure content validity and clarity of instructions. Most of the questions used a 5-point Likert scale, but respondents could also supply free-text responses. The survey consisted of a few general questions, as well as questions about the 4 computer-mediated conferencing sessions, to determine ease of use of and preceptors' comfort with the technology, overall satisfaction with the program, utility of the tools and strategies discussed, utility of sharing experiences through the computer-mediated conferencing sessions, preceptors' confidence and feelings of support, and the influence of the program on willingness to serve as a preceptor in the future. Two pharmacists (M.L.A., M.R.) and one educator independently reviewed the survey results and identified themes, with subsequent discussion to refine the themes. Following survey analysis, study participants were invited to attend a virtual feedback session. Each webconferencing session was led by an independent facilitator, and the themes for discussion were based on the survey results.

\section{RESULTS}

A total of 122 preceptors participated in the phase 1 workshop, representing more than three-quarters of potential preceptors within the Edmonton Zone of AHS. According to preceptor assignments in the specified time frames and practice areas, 39 of these preceptors were invited to participate in the computer-mediated conferencing (Table 3).

The computer-mediated conferencing sessions took place during 2 separate 6-week rotation blocks. The first block involved 16 pharmacists working in inpatient medicine (specifically internal medicine, family medicine) and related subspecialties, and the second block involved 23 pharmacists with ambulatory practices affiliated with AHS_Edmonton Zone (predominantly in hospital-based clinics) or various inpatient practices (specifically family medicine and surgery). Survey results for the 2 groups were combined, and no preceptors participated in both rotation blocks. A total of 26 (67\%) of the 39 preceptors responded to the electronic survey, although some respondents did not answer all questions. Of the 4 virtual feedback sessions initially planned, 2 were cancelled because of a lack of participants, and a total of 6 preceptors 


\section{Table 3. Participation in Project}

Phase and Dates

Phase 1: Workshopt

Phases 2 and 3: Computer-mediated conferencing

Internal medicine groups (October to December 2009)

Family medicine group and internal medicine subspecialties (October to December 2009)

Ambulatory practice group (January and February 2010)

Family medicine and surgery group (January and February 2010)

Subtotal

\section{Evaluation of computer-mediated conferencing}

*Attendance in computer-mediated conferencing sessions was not mandatory and was not recorded.

†Dates of workshops: February, June, September, October, and November 2008; January (2), February,

March, September, and October 2009.

(15\%) attended the other 2 sessions. The results of qualitative feedback during these 2 sessions were combined.

About half (13/25 [52\%]) of the survey respondents were experienced, having served as a preceptor for at least 5 students over the preceding 5 years. Well over half $(15 / 25$ [60\%]) were employed in facilities with more than 500 beds. More than $90 \%(22 / 24)$ of respondents indicated that this was their first experience with computer-mediated conferencing. Although $70 \%(14 / 20)$ of respondents agreed or strongly agreed that the technology was easy to use, only $50 \%(11 / 22)$ agreed that they were very comfortable with the technology, and 43\% (9/21) reported technical problems while using the system. Nearly three-quarters (15/21 [71\%]) of respondents reported an increasing level of comfort with the technology as the sessions progressed, but only $50 \%(11 / 22)$ reported an increasing level of active participation in the sessions.

There was a drop-off in attendance as the sessions progressed: $70 \%(16 / 23)$ of respondents reported attending the first session and $81 \%(17 / 21)$ the second, but only $45 \%(9 / 20)$ and 33\% (7/21) reported attending the third and fourth sessions, respectively. The most commonly cited reason for not attending was inconvenience of the selected date or time, although some respondents indicated that inability to leave other work duties was also a factor. Such issues were more prominent for those working at smaller sites. Some respondents found the sessions too long, a factor that was compounded by technological difficulties. Some preceptors indicated that fewer sessions would be preferable and that it would helpful to have more information about the discussion topics in advance.

The first 2 sessions dealt with use of the technology for computer-mediated conferencing, as well as planning for the rotation and student orientation (Table 2). The majority (20/26 [77\%]) of respondents agreed that the timing of these 2 sessions was appropriate in relation to the rotation schedule. In general, discussion during these sessions was perceived to be helpful, as were the various tools that were shared. However, respondents were divided about the utility of the sessions for planning rotations. Only 33\% (4/12) and 40\% (6/15) of respondents agreed that the first and second sessions, respectively, were a productive use of their time, and these sessions were deemed useful primarily for new or inexperienced preceptors or as refreshers.

The third session involved a coordinator from the Faculty of Pharmacy and Pharmaceutical Sciences, who presented an innovative model for delivering feedback. More than half $(3 / 5$ [60\%]) of respondents felt that this session was a productive use of their time, regardless of their previous experience, and stated that they would attempt to use this feedback model. During the session, participants observed a video broadcast of a student interacting with a standardized patient and then discussed the content and method of delivering feedback to the student. Unfortunately, the audiovisual quality was poor, which frustrated a number of participants.

The final session focused on methods of evaluating students. The majority ( $4 / 5[80 \%])$ of respondents felt that this was a productive session and that it would be a good refresher even for experienced preceptors.

Overall, the majority (9/16 [56\%]) of respondents found it useful to share information and experiences with other preceptors. They felt supported by their assigned clinical practice leaders with respect to their preceptor activities, and the sessions enhanced their sense of being part of a community. Experienced preceptors felt more supported by the Faculty of Pharmacy and Pharmaceutical Sciences than did newer preceptors. In general, preceptors felt that they gained new skills from the sessions, but only some respondents reported an increase in their confidence in supervising students and delivering negative feedback. Less experienced preceptors found sharing more useful, were more likely to use the information, and were more likely to feel that the sessions improved their confidence than was the case for more experienced preceptors. Most respondents indicated that they would use the information provided, either during the current rotation or, more commonly, during future rotations.

When asked, respondents indicated that the computermediated conferencing sessions would not necessarily encourage them to serve as preceptors more frequently. However, they did feel that the sessions would encourage them to continue undertaking this activity regularly. Most respondents (16/18 [89\%]) stated that they would take students on rotation in the future, 
and about three-quarters $(13 / 17$ [76\%]) indicated that they would attend computer-mediated conferencing sessions again if they were serving as preceptors. More experienced preceptors felt that these sessions were beneficial and a useful venue to discuss challenging students. They also felt that the sessions would be a useful refresher and would be more interesting if the topics changed from year to year.

One theme of discussion during the virtual feedback sessions was an exploration of the reasons for not attending the computer-mediated conferencing sessions. Technology-related issues, such as lack of familiarity and problems with the computer equipment, scheduling conflicts, and difficulty balancing the competing priorities of staff pharmacist workload, preceptor responsibilities, and session attendance were commonly cited. Participants provided suggestions to alleviate scheduling difficulties, including scheduling the sessions on specific days of the week or at specific times, providing greater advance notice, and soliciting preceptors' scheduling preferences, as well as making recordings of the sessions available to those unable to participate at the scheduled time.

Participants also suggested various strategies to improve discussion during the sessions, including making discussion questions available in advance and encouraging experienced preceptors to share more of their experiences. Respondents would have preferred the session on strategies for managing challenging students to occur earlier in the rotation. There was also interest in including other topics and incorporating sessions on skill-building.

\section{DISCUSSION}

Overall, this pilot project was successful and well received by participants. The networking appealed to most preceptors, regardless of experience. This result was consistent with the goal of building a sense of community among preceptors. More experienced preceptors found the sessions on planning rotations and orienting students less productive than did those with less experience. However, experienced preceptors still found the discussions helpful, which reflects the importance of networking. Technology has been used extensively to support preceptors and to build professional communities, but to our knowledge this is the first use of synchronous computer-mediated conferencing for preceptor support. The use of asynchronous technologies, such as listservs and online discussion boards, is more commonly reported. ${ }^{1-7}$

The determinants of success for online communities are likely specific to the settings and participants, but the literature offers certain common themes, ${ }^{6}$ including appropriate technology, a respectful environment, relevant discussions, willingness of participants to share knowledge, high-quality content, diversity of views, and rapid response to participant queries. A number of these themes were consistent with issues identified in this project, as discussed below.
Although the use of technology for professional development is generally positive in terms of participants' learning experiences, including peer support, ${ }^{1,47}$ challenges certainly exist ${ }^{1,4.7}$ and can reduce the level of participation. ${ }^{6}$ Technology challenges can be categorized in terms of ease of use, reliability, and accessibility of information. ${ }^{6}$ Adequate time and appropriate technical support, which may extend to in-person computer training, ${ }^{7}$ are required to learn and use technological tools. In the study reported here, despite the availability of an xperienced technical support person during each session, participants identified technology challenges as an issue that limited their participation. Technology support, both in advance from the information systems department, to ensure compatibility of the technology with existing computer systems, and during the sessions, to ensure that preceptors can participate, is required. Further investigation is needed to determine the best technology for this type of conferencing and its optimization.

A respectful environment and relevant discussion are related to facilitation. Self-selection of participants may also contribute to engagement. This was partially true of this pilot study, as not all invited preceptors participated. Electronic communities require a high level of assistance from an active facilitator during the learning process, ${ }^{7.8}$ and the importance of this role continues beyond the initial establishment of the group. ${ }^{1,4,6}$ The setting of ground rules for handling the technology was a component of this and other projects. ${ }^{6}$ Conversely, in one study, computer-mediated conferencing was discontinued because of lack of facilitation and hence lack of meaningful discussions. ${ }^{7}$ Facilitators have a number of roles, and training may be needed to ensure that they can fulfill all of these roles in a virtual environment.' Although the clinical practice leaders at AHS-Edmonton Zone were experienced in facilitating face-to-face sessions, they had limited experience with facilitation in a virtual setting. They participated in an educational session before beginning this project, but additional sessions would likely have been helpful.

With respect to the specific goal of developing literature and resource templates, the facilitator perceived that the group needed a starting point, such as a partial list, to focus the task. Revision of existing resources may not appear as daunting as initial development. Clinical practice leaders should encourage experienced preceptors to develop and share such templates during nonrotation periods.

Several issues related to the hospital environment were identified as affecting the success of the computer-mediated conferencing sessions, ranging from difficulty finding a quiet workspace equipped with a computer ${ }^{1}$ to more complex issues related to scheduling the sessions in conjunction with other work duties. More specifically, the sessions must be scheduled to fit better into the time that preceptors have available. Although use of asynchronous technology addresses such scheduling problems, it does not resolve the broader issue of 
competing workload demands and in fact may negatively affect work-life balance. ${ }^{1}$ In addition, the use of asynchronous technology has been reported to diminish interactions among learners, ${ }^{4}$ and, in at least one program, preceptors did not utilize the available asynchronous resources. ${ }^{10}$ Solving scheduling problems and making it possible to leave other duties will require collaboration with management and administrative support. In this study, we did not ascertain whether preceptors approached their managers about these challenges. The literature indicates that support for protected time must come from senior leadership. ${ }^{1}$ In addition, the importance of the network of preceptors must be recognized within the organization to ensure broad acceptance of the time commitment required.?

Time constraints were a major barrier to networking identified in this and other studies, ${ }^{17,8,11}$ and the use of technology did not solve this problem. Preceptors typically feel that they do not have enough time to perform their regular duties, so the addition of more than 4 hours of online meeting time was an extra burden.

Technology has benefits but does not seem to be a substitute for periodic sharing in a face-to-face setting. A common theme from the workshop evaluations was participants' enjoyment of the opportunity to hear and learn from the experiences of their peers. The virtual conferencing sessions followed inperson workshop attendance but not necessarily with the same group of participants. Face-to-face meetings may increase familiarity and build deeper social ties among participants, thereby contributing to interactions during virtual sessions. ${ }^{6}$

This pilot project had several limitations because of the small sample size, the qualitative evaluation, and the lack of evaluation over repeated preceptorship experiences. Because the computer-mediated conferencing platform was provided through the province's faculty of pharmacy and because many individuals provided assistance over the course of the project, it was difficult to quantify the resources required to provide this type of support to preceptors. However, we were able to demonstrate the feasibility of both supporting preceptors through computer-mediated conferencing and building a sense of community and peer support with technology. This pilot project also allowed us to identify some of the challenges inherent to this type of support. Recommendations arising from this project include the need to determine the best type of platform for this purpose, work with information technology at both an oversight and a local level, and give preceptors both the appropriate space and scheduled time to participate. Our success and challenges with this type of support are likely generalizable to the majority of health regions with multiple sites, where face-to-face support is impractical.

\section{CONCLUSIONS}

As needs for experiential learning for the pharmacy profession expand, the ability to use technology for training and supporting preceptors, without geographic restriction, will become increasingly important. Although preceptors in this study did not indicate that conferencing sessions would encourage them to serve as preceptors more frequently, they were encouraged to continue regularly serving in this role. Retention of preceptors is an essential component to maintaining current capacity, and its importance should not be overlooked.

\section{References}

1. Allan B, Lewis D. Virtual learning communities as a vehicle for workforce development: a case study. J Workplace Learn 2006;18(6):367-383.

2. Boyle J, Tolmie A, Stobie I. Bridging the gap: probationer educational psychologists' use of computer-mediated conferencing. Educ Psychol Pract 2003;19(3):189-197.

3. Bramson R, Vanlandingham A, Heads A, Paulman P, Mygdal W. Reaching and teaching preceptors: limited success from a multifaceted faculty development program. Fam Med 2007;39(6):386-388.

4. Curran V, Kirby F, Parsons E, Lockyer J. Discourse analysis of computermediated conferencing in World Wide Web-based continuing medical education. J Contin Educ Health Prof 2003;23(4):229-238.

5. Dalton L, Bull R, Taylor S, Galbraith K, Marriott J, Howarth H. Evaluation of the national pharmacy preceptor education program. Aust $J$ Rural Health 2007;15(3):159-165.

6. Hew KF. Determinants of success for online communities: an analysis of three communities in terms of members' perceived professional development. Behav Inform Technol 2009;28(5):433-445.

7. Lau F, Hayward R. Building a virtual network in a community health research training program. J Am Med Inform Assoc 2000;7(4):361-377.

8. Wilson LL, Bodin MB, Hoffman J, Vincent J. Supporting and retaining preceptors for NNP programs: results from a survey of NNP preceptors and program directors. J Perinat Neonatal Nurs 2009;23(3):284-292.

9. Sargeant J, Curran V, Allen M, Jarvis-Selinger S, Ho K. Facilitating interpersonal interaction and learning online: linking theory and practice. J Contin Educ Health Prof 2006;26(2):128-136.

10. Kruzich LA, Anderson J, Litchfield RE, Wohlsdorf-Arendt S, Oakland MJ. A preceptor focus group approach to evaluation of a dietetic internship. J Am Diet Assoc 2003;103(7):884-886.

11. Davison M, Medina MS, Ray NE. Preceptor preferences for participating in electronic preceptor development. Pharm Pract 2009;7(1):47-53.

Margaret L Ackman, BSc(Pharm), PharmD, FCSHP, is a Clinical Practice Leader, Alberta Health Services, Edmonton, Alberta.

Marcel Romanick, BScPharm, is a Clinical Practice Leader, Alberta Health Services, Edmonton, Alberta.

\section{Address correspondence to:}

Dr Margaret L Ackman

Alberta Health Services

0G1.01 Walter Mackenzie Centre

8440 - 112 Street NW

Edmonton $A B$ T6G 1V5

e-mail: margaret.ackman@albertahealthservices.ca

\section{Acknowledgements}

We would like to acknowledge Nicole Luchkow, BA, MDE, for assisting and supporting the computer-mediated conferencing and for collating data from the electronic survey and virtual feedback sessions. We would also like to thank the clinical practice leaders who facilitated the computer-mediated conferencing sessions and our committed preceptors for their enthusiasm and interest in improving 